\title{
Back-Surface Passivation of CdTe Solar Cells using Solution- Processed Oxidized Aluminum
}

\author{
Fadhil K. Alfadhili, Adam B. Phillips*, Kamala Khanal Subedi, Craig L. Perkins, Adam I. Halaoui, Manoj \\ K. Jamarkattel, Bhuiyan M. Anwar, Geethika K. Liyanage, Deng-Bing Li, Corey R. Grice, Yanfa Yan, \\ Randy J. Ellingson, and Michael J. Heben \\ Wright Center for Photovoltaics Innovation and Commercialization, Department of Physics and \\ Astronomy, University of Toledo, Toledo, Ohio, 43606, United States \\ National Renewable Energy Laboratory, Golden, Colorado, 80401, United States \\ *Corresponding Author: adam.phillips@utoledo.edu
}

\section{Experimental Details}

The surface morphology was examined using atomic force (AFM; Veeco NanoScope V) and surface characterization were completed using x-ray photoemission spectroscopy (XPS) and Auger electron spectroscopy (AES). XPS was performed on a Physical Electronics 5600 system using monochromatic Al $\mathrm{K}_{\alpha}$ radiation with the sample at near-normal take-off angle and with a pass energy of $11.75 \mathrm{eV}$. Auger electron spectroscopy was done at NREL using a Physical Electronics 710 scanning Auger nanoprobe and with a $10 \mathrm{kV} 10 \mathrm{nA}$ primary beam. AES spectra were acquired in direct mode, numerically differentiated, and peak-to-peak heights in the differentiated spectra were used as a measure of elemental abundance. Samples were analyzed "as-received" from the University of Toledo and without surface cleaning, i.e. were exposed to air after treatment with alumina/sol-gel in order to replicate surface conditions used for optical characterization. Analysis of both XPS and AES data was done using literature sensitivity factors in PHI MultiPak v9.7.1.7.

Current density voltage (J-V) curves were measured under simulated AM1.5G solar irradiation (Newport model 91195A-1000) using a Keithley 2400 source meter. The external quantum efficiency (EQE) measurements were acquired from wavelength range of 300-900 nm using a PV Measurements Inc., model IVQE8-CQE system.

For photoluminescence (PL) measurements, the samples were excited through the film side with a $3.1 \mathrm{~W} / \mathrm{cm}^{2} 532 \mathrm{~nm} \mathrm{cw}$ laser with diameter $\sim 100 \mu \mathrm{m}$. PL signals were detected by a Horiba Symphony-II CCD detector with a $0.5 \mathrm{~s}$ integration time following a $300 \mathrm{~g}-\mathrm{mm}^{-1}$ grating monochromator [1].

The room temperature time-resolved photoluminescence (TRPL) measurements of CdTe samples were performed with a $532 \mathrm{~nm}$ pulsed laser with beam diameter $\sim 150 \mu \mathrm{m}$ and photon fluence is $1.5 \times 10^{10}$ photons $\mathrm{cm}^{-2}$ pulse-1) with the repetition rate of $20 \mathrm{MHz}$ when the samples are excited through the film side at the peak emission wavelength $810 \mathrm{~nm}$ determined from the PL measurement. The TRPL measurements of CdTe samples were performed with time correlated single photon counting (TCSPC) module with integration time $300 \mathrm{~s}$. A Horiba iHR320 monochromator is used to select the detection wavelength using high speed hybrid detector from Becker \& Hickl [2]. 


\section{Supporting Information}

\section{$\underline{\text { Steady-State PL and TRPL Data }}$}

Figure S1 shows the steady state PL and TRPL graphs acquired for the CdTe devices as a function of $\mathrm{Al}_{2} \mathrm{O}_{3}$ cycles, and Table SI shows a table of the measured $\tau_{1}$ and $\tau_{2}$ with their respective yields. The intensity of the PL response increases monotonically as the number of cycles increases from 1 to 5 cycles; however, when 7 or 9 cycles are used, the intensity decreases from the high but remain above that of the bare CdTe. Likewise, the long lifetime component of the TRPL, T2, significantly increased as the number of cycles increased from 0 to 7 cycles of $\mathrm{Al}_{2} \mathrm{O}_{3}$ and dropped slightly as the number of cycles went from 7 to 9 . These measurements showed that the minority carrier lifetime increased with the number of cycles, as did the $\mathrm{V}_{\mathrm{oc}}$ of the finished devices.

In case of bi-exponential PL decay, the photoluminescence intensity contribution of each component is proportional to the product of amplitude $\left(\mathrm{A}_{\mathrm{i}}\right)$ and lifetime $\left(\tau_{\mathrm{i}}\right)$. In addition to all the measurements are done by maintaining a low -injection level of photo-generated carrier density $1.7 \times 10^{14}$ $\mathrm{cm}^{-3}$. The TRPL decay curve is the convolution of the decay profile of the samples and the system response function (SRF). Accurate determination of the carrier lifetime is the results of an iterative re-convolution fitting routine between the measured SRF and bi-exponential test function. From analysis process reduced Chi-square value is close to 1 . There is no variation of the slope.
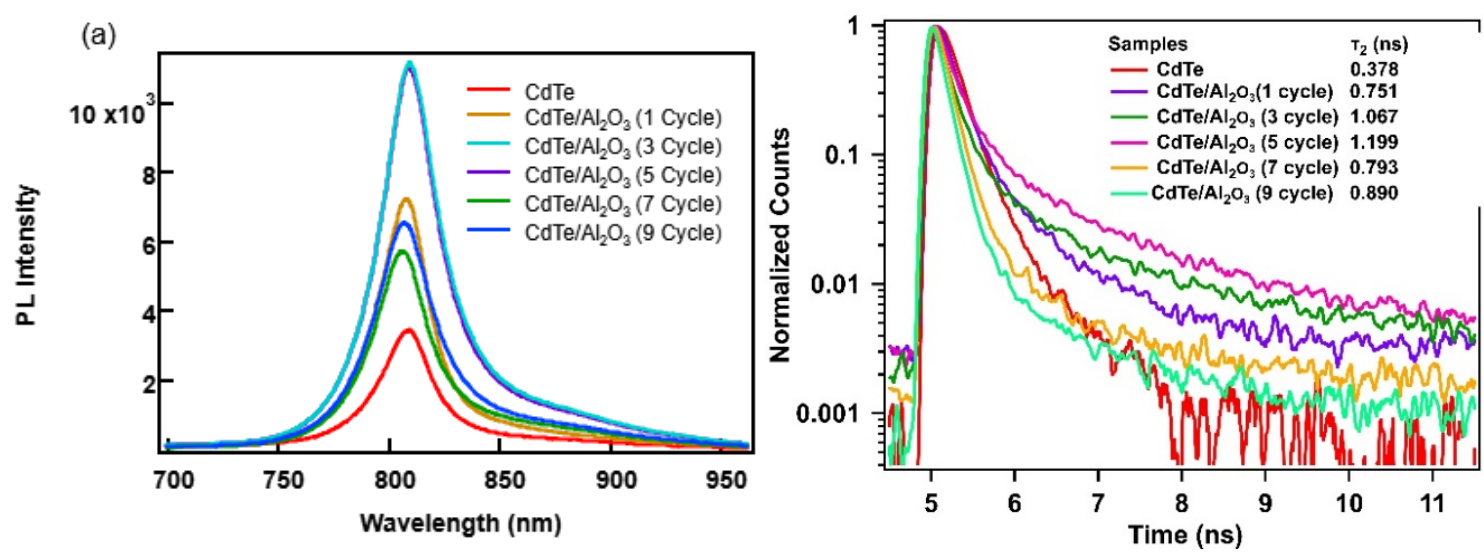

Figure S1: (a) The average PL spectrum of the CdS/CdTe thin film solar cell passivated by using the $\mathrm{Al}_{2} \mathrm{O}_{3}$. (b) TRPL decay of the CdS/CdTe thin film solar cell passivated by using the $\mathrm{Al}_{2} \mathrm{O}_{3}$.

Table S1: Lifetime measurement of the CdS/CdTe solar cell.

\begin{tabular}{|l|l|l|l|l|}
\hline Samples & Tau1 (ns) & Yield 1\% & Tau2 (ns) & Yield 2\% \\
\hline E1H3(STD) & $0.054 \pm 0.007$ & $75.6 \pm 1.38$ & $0.387 \pm 0.03$ & $24.4 \pm 1.38$ \\
\hline E1D2(1 Cycle) & $0.048 \pm 0.014$ & $63.8 \pm 3.2$ & $0.751 \pm 0.11$ & $36.2 \pm 3.2$ \\
\hline E1D3 (3 Cycle) & $0.088 \pm 0.002$ & $55.0 \pm 2.3$ & $1.067 \pm 0.008$ & $45.0 \pm 2.3$ \\
\hline E1D4(5 Cycle) & $0.074 \pm 0.001$ & $61.5 \pm 2.7$ & $1.199 \pm 0.008$ & $38.5 \pm 2.7$ \\
\hline E1D5(7 Cycle) & $0.034 \pm 0.009$ & $69.2 \pm 1.8$ & $0.793 \pm 0.104$ & $30.8 \pm 1.8$ \\
\hline E1D6 (9 Cycle) & $0.023 \pm 0.010$ & $71.2 \pm 0.5$ & $0.890 \pm 0.055$ & $28.8 \pm 0.5$ \\
\hline
\end{tabular}




\section{Supporting Information}

\section{Auger Electron Spectroscopy}

Figure $\mathrm{S} 2$ shows the AES map images for $\mathrm{Cd}$, Te, and $\mathrm{Al}$ for 1 and 5 cycles of $\mathrm{Al}_{2} \mathrm{O}_{3}$ samples. Note that the for the measurement of the sample with 1 cycle the sample tilt was set to $0^{\circ}$ while for the measurement for the sample with 5 cycles the sample tilt was set to $30^{\circ}$. This difference may account for what appears to be an increasing contribution from topographic features in the five cycle sample. In the 1 cycle case, the $\mathrm{Al}$ is very near the detection threshold and does not show high concentrations at any point. As expected, more Al was detected on the 5 cycle sample, and it does not appear to correlate to any specific features of the underlying materials. Table SII shows the AES-derived surface composition for CdTe samples with 1 and 5 coating cycles $\mathrm{Al}_{2} \mathrm{O}_{3}$. Note that the composition results assume a uniform composition within the $\sim 10 \mathrm{~nm}$ probe depth of the measurement. The relatively high carbon, oxygen, and chlorine signals detected are not unusual for the film-side surfaces of $\mathrm{CdTe}$ that has undergone $\mathrm{CdCl}_{2}$ treatment. The decrease in chlorine $\mathrm{Cl}$ with increasing number of cycles could be due to either removal of chlorine by the alumina treatment, burial of chlorine by an alumina overlayer, or both effects. The $\mathrm{C}$ and $\mathrm{O}$ may be related to exposure to the environment or residue from the precursor material.

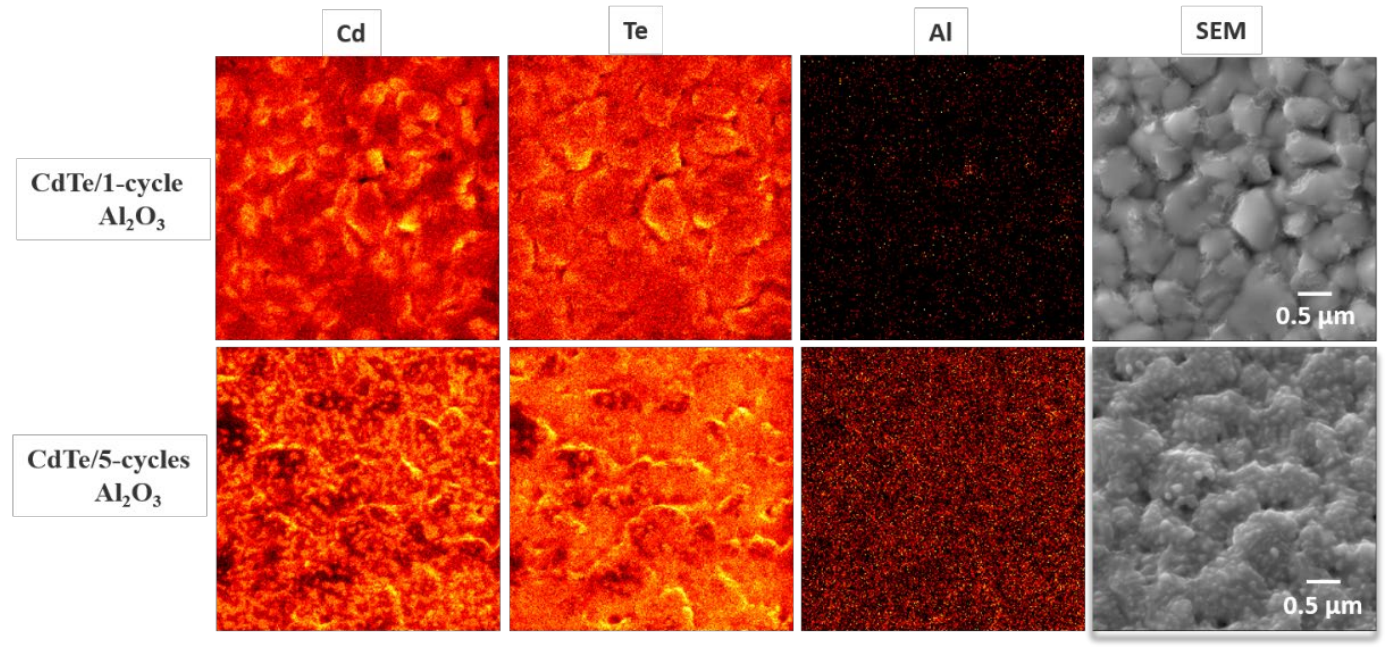

Figure S2: Elemental maps of the back surface of a $\mathrm{CdTe} / 1$ and 5-cycles $\mathrm{Al}_{2} \mathrm{O}_{3}$ stack obtained using Auger electron spectroscopy. The field of view for the AES maps are the same as that of the SEM image. 


\section{Supporting Information}

Table S2: AES results of 1 and 5 coating cycles of $\mathrm{Al}_{2} \mathrm{O}_{3}$ on CdTe films. Note the measurements were performed with an accelerating potential of $10 \mathrm{kV}$, and the beam diameter was $\sim 10 \mathrm{~nm}$.

\begin{tabular}{|c|c|c|}
\hline \multirow{2}{*}{ Element } & $\begin{array}{c}\text { CdTe/1-cycle } \\
\mathbf{A l}_{2} \mathbf{O}_{3}\end{array}$ & $\begin{array}{c}\text { CdTe/5-cycles } \\
\mathbf{A l}_{2} \mathbf{O}_{3}\end{array}$ \\
\cline { 2 - 3 } & $\begin{array}{c}\text { Atomic } \\
\text { Concentration } \\
(\%)\end{array}$ & $\begin{array}{c}\text { Atomic } \\
\text { Concentration } \\
(\%)\end{array}$ \\
\hline $\mathbf{C}$ & 29.61 & 44.88 \\
\hline $\mathbf{O}$ & 26.45 & 26.30 \\
\hline $\mathbf{A l}$ & 5.60 & 15.06 \\
\hline $\mathbf{C l}$ & 4.65 & 1.32 \\
\hline $\mathbf{C d}$ & 14.83 & 4.39 \\
\hline $\mathbf{T e}$ & 18.86 & 8.04 \\
\hline
\end{tabular}

Figure $\mathrm{S} 3$ shows an expanded view of the SEM image of the CdTe stack with 5 cycle $\mathrm{Al}_{2} \mathrm{O}_{3}$. With the higher resolution image, locations of potential terrace reconstruction can be seen.

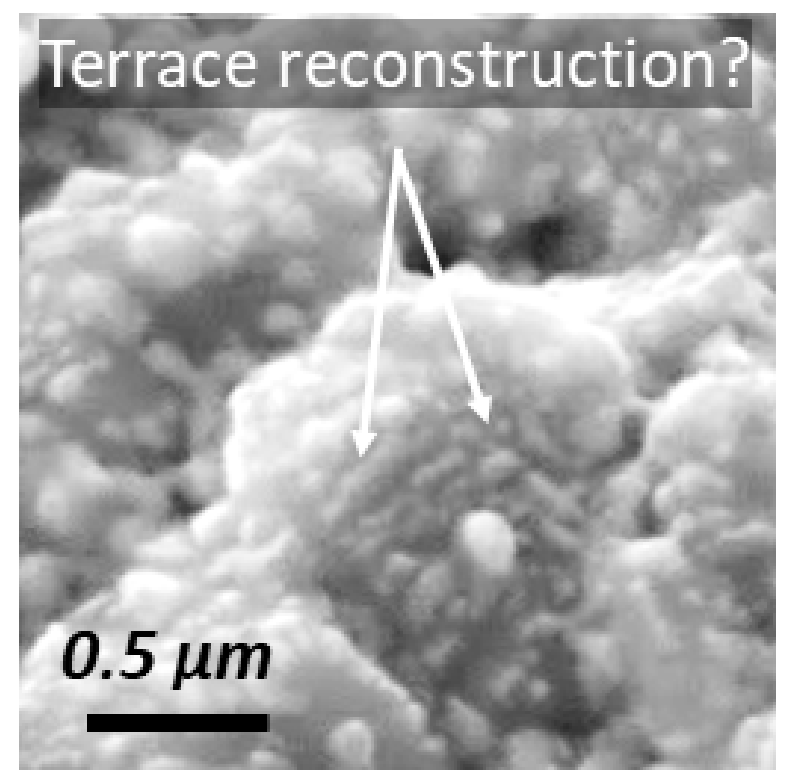

Figure S3: High resolution SEM image of $\mathrm{CdTe} / 5$ cycle $\mathrm{Al}_{2} \mathrm{O}_{3}$ stack that shows potential terrace reconstruction that may occur during $\mathrm{Al}(\mathrm{acac})_{3}$ processing. 


\section{Supporting Information}

\section{Infrared spectroscopy}

Figure S4 shows the Fourier transform infrared (FTIR; Thermo Scientific Nicolet \#6700) spectra of a $1 \mu \mathrm{m}$ thick precursor layer prepared by blade coating on soda lime glass before and after the annealing. Prior to annealing, the IR spectra exhibits several peaks between $1700-500 \mathrm{~cm}^{-1}$ which are corresponding to the organic components of AcAc. Hoverer, after the annealing, the spectra shows only absorption features at $1000-500 \mathrm{~cm}-1$ which is related to $\mathrm{Al}_{2} \mathrm{O}_{3}[3]$.

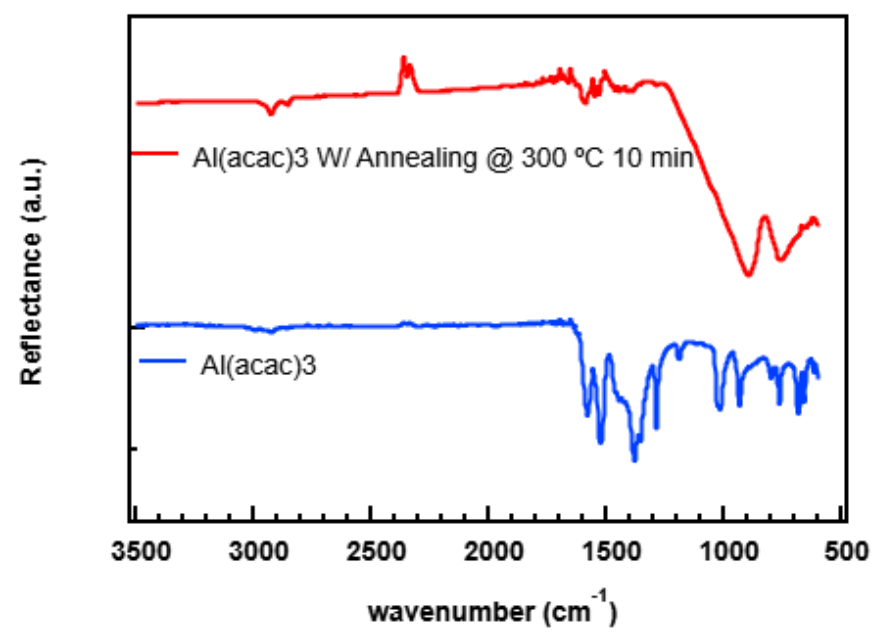

Figure S4: Infrared spectra reflectance for a $1 \mu \mathrm{m}$ thick precursor layer prepared by blade coating on soda lime glass before and after the annealing.

\section{$\underline{\text { Atomic Force Microscopy (AFM) }}$}

Figure S5 shows AFM images of the surface of CdTe with and without $\mathrm{Al}_{2} \mathrm{O}_{3}$. These images show that the deposited aluminum was not formed in a uniform layer and was present in very small amounts, suggesting that the passivation effects maybe be site- and/or facet-specific.

$647.6 \mathrm{~nm}$

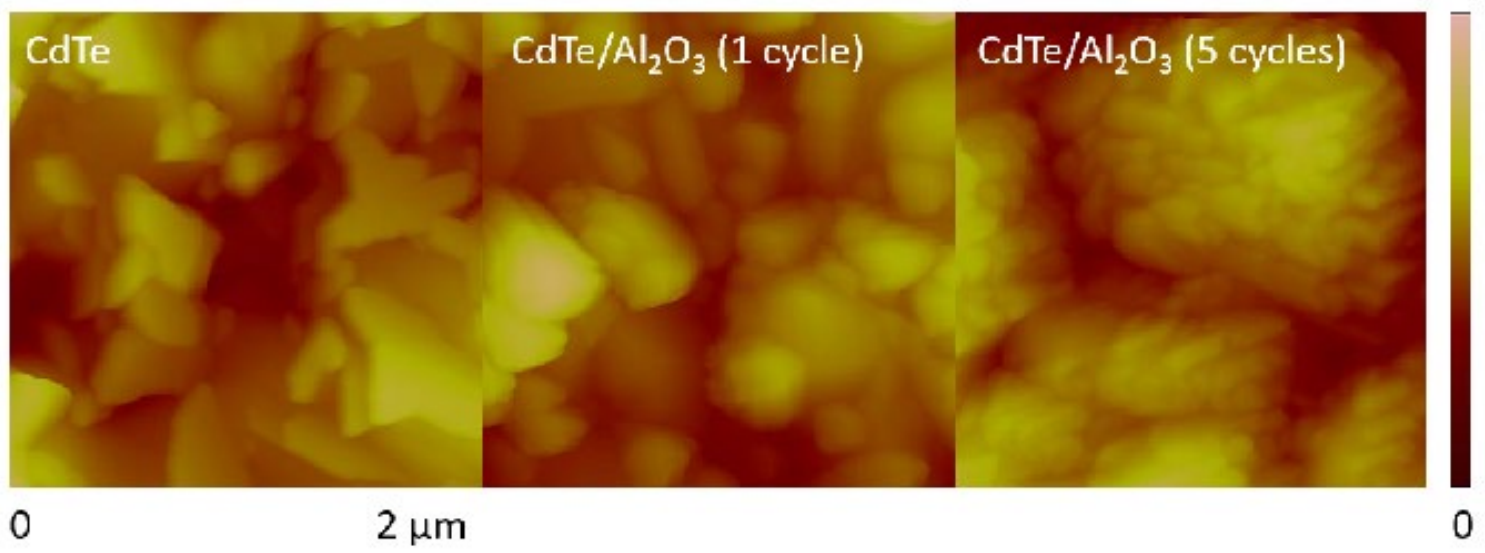

Figure S5: (left) The AFM images of CdTe, (center) of $\mathrm{CdTe} / \mathrm{Al}_{2} \mathrm{O}_{3}\left(1\right.$ cycle), and (right) of $\mathrm{CdTe} / \mathrm{Al}_{2} \mathrm{O}_{3}$ (5 cycles) samples. 


\section{Supporting Information}

\section{External Quantum Efficiency Measurements with Bias Voltage}

Figure S6 a and $\mathrm{b}$ show the forward biased EQE measurements for CdS/CdTe device with and without $\mathrm{Al}_{2} \mathrm{O}_{3}$. For both these samples, it was found that current collection decreased as the forward bias increased due to a reduction in the electrical field through the absorber layer. As discussed in the main text, both samples have the same EQE at short circuit, but a downward slope emerges at long wavelengths for the device with $\mathrm{Cu} / \mathrm{Au}$ but not in the device with $\mathrm{Al}_{2} \mathrm{O}_{3}$ as the bias increases. This change in slope indicates increased recombination at the back interface of the device.
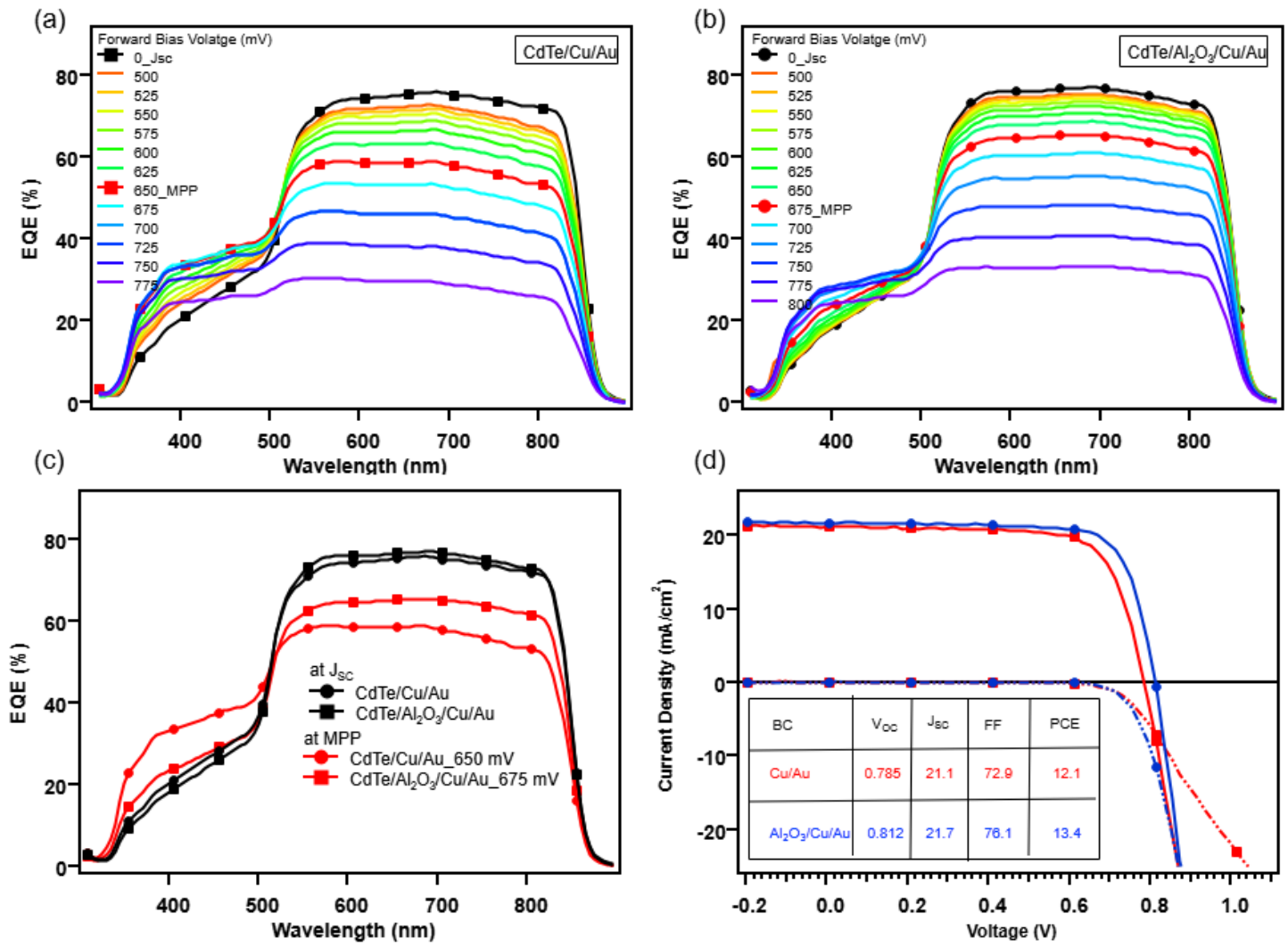

Figure S6: Bias dependent EQE measurements for (a) $\mathrm{CdTe} / \mathrm{Cu} / \mathrm{Au}$ and (b) $\mathrm{CdTe} / \mathrm{Cu} / \mathrm{Al} 2 \mathrm{O} 3$ (one cycle)/Au devices. (c) EQE measurements at short circuit and maximum power point for both devices. (d) $\mathrm{J}-\mathrm{V}$ curves for both devices.

\section{$\underline{\text { References }}$}

[1] S. C. Watthage, Z. Song, N. Shrestha, A. B. Phillips, G. K. Liyanage, P. J. Roland, et al., "Enhanced Grain Size, Photoluminescence, and Photoconversion Efficiency with Cadmium Addition during the Two-Step Growth of CH3NH3PbI3," ACS Applied Materials \& Interfaces, vol. 9, pp. 23342341, 2017/01/25 2017.

[2] P. J. Roland, N. R. Paudel, X. Chuanxiao, Y. Yan, and R. J. Ellingson, "Photoluminescence spectroscopy of Cadmium Telluride deep defects," in 2014 IEEE 40th Photovoltaic Specialist Conference (PVSC), 2014, pp. 3266-3271.

[3] T. Maruyama and S. Arai, "Aluminum oxide thin films prepared by chemical vapor deposition from aluminum acetylacetonate," Applied Physics Letters, vol. 60, pp. 322-323, 1992. 
Supporting Information 